\title{
Mechanical Performance of Curved Link-Slab of Simply Supported Bridge Beam
}

\author{
Yizhou Zhuang, ${ }^{1}$ Silv Luo, ${ }^{1}$ Said M. Easa, ${ }^{2 *}$ Meng Zhang, ${ }^{1}$ and Chengquan Wang, ${ }^{3}$ \\ ${ }^{1}$ College of Civil Engineering, Zhejiang University of Technology, Hangzhou 310014, Zhejiang, P. R. China. \\ ${ }^{2}$ Department of Civil Engineering, Ryerson University, M5B 2K3, Toronto, Ontario, Canada. \\ ${ }^{3}$ School of Environment and Civil Engineering, Jiangnan University, Wuxi 214122, P. R. China. \\ *Correspondence: seasa@ryerson.ca
}

Abstract: This paper proposes a curved link-slab (CLS) structure, simplified into a hingeless-arch model, to

address the current cracking phenomenon of CLS concrete. The stress formula of the hingeless arch under

various loads is derived based on the classical mechanic's method. Based on an actual bridge example, the mechanical properties of CLS are analyzed under different loads and load combinations. The results show that: (1) the CLS stress is significantly lower than that of the flat link-slab structure (FLS), (2) its stress values are less than the concrete tensile limit, and (3) the CLS can effectively solve the concrete cracking phenomenon on the link-slab. The rationality of the stress formula derived from the simplified model of the hingeless arch is verified using the finite element method (FEM). The parametric sensitivity analysis shows that variation of the reinforcement ratio of the CLS has a limited impact on it. Considering both the concrete tensile and compressive limit, the thickness of the CLS should be $15 \mathrm{~cm}$ to $20 \mathrm{~cm}$, and its design span should be about $5 \%$ to $7.5 \%$ of the main beam length.

Keywords: Curved link-slab; Hingeless arch; Theoretical derivation; Parametric sensitivity analysis.

\section{INTRODUCTION}

The flat link-slab (FLS) application at the top of the pier for a multi-span bridge is common, but it is easy to crack (Chen and Zhuang, 2019; Matt, 1983; Fan, 1984). Due to the FLS location, the stress and deformation are complex, and the engineering quality is difficult to guarantee. The concrete on the FLS can easily crack, and the cracks aggravate the bridge deck damage, the formation of potholes, rainwater infiltration, and corrosion of the steel bars. This distress would seriously affect the strength and durability of the FLS structure 
and reduce the life cycle of the bridge (Yao, 2005; Su and Yang, 2005).

To solve the existing problems of the FLS, researchers worldwide have put forward practical solutions for different issues of bridge decks through long-term experimental research and engineering practice. Caner and Zia (1998) conducted experiments on the FLS of simply-supported beams (SSB), analyzed the mechanical properties of the longitudinal main beams with different spans, and proposed a theoretical FLS design method based on the three-moment equation. Charuchaimontri and Senjuntichai . (2008) studied the influence of various boundary conditions on the FLS, which are usually constructed in Thailand using a three-dimensional nonlinear finite element code based on the microplane model and obtained the loaddeflection curve of the FLS. Based on the internal forces and cracks, a design standard for the FLS was formulated.

Au and Lam (2013) applied the debonding link-slab system to repair the FLS, replaced the expansion device, and conducted a long-term cyclic loading test. The test results show that the system meets bridge design requirements under the (service) limit state. Chen and Abu-Farsakh . (2015) proposed a new bridge end-slab design method that can increase the flexural rigidity of the slab. Then, the authors showed that the newly designed slab has better performance than the traditional design through the static loading tests. Kim and Fischer, Y. (2004) proposed a ductile Engineered Cementitious Composite (ECC) bridge-deck connecting plate. The deflection and fatigue properties of the ECC connecting plate were experimentally studied. The research showed that the deflection ability of the ECC connecting plate and the crack width control ability could effectively extend the continuous service life of the bridge deck.. Ahn and Yoon (2011) put forward a simplified model of a monolithic jointless bridge, calculated the internal force of the FLS under temperature load through FEM and simplified the theoretical model. The mechanical properties of the integral jointless bridge under the static load were obtained. 
Kendall and Keoleian (2008) applied a new composite-concrete material to the FLS. The results showed that the material has the advantage of not being easily damaged and can increase the FLS life cycle. Saber and Aleti (2012) applied a new fibre-reinforced composite plastic material to the FLS. It was found that the composite plastic could reduce the corners at both ends of the main beam. The structure of the composite plastic link-slab has the advantages of being resistant to damage and easy to repair. Wang and Xie (2014) proposed a new arched link-slab device for bridge decks over piers, which changed the FLS internal force transmission method. Through loading tests, the authors showed that the structure could improve the anticracking damage of the bridge deck. Wang and Shen (2016) proposed an arched link-slab structure suitable for the deck of hollow slab girder bridges. The numerical simulation was modeled to analyze the mechanical characteristic of arched link-slab. Proper parameters of the arch span and rise were obtained using theory deduction and numerical calculations. This study verified the effectiveness of the structure of the hollow slab girder arch link-slab to prevent concrete from cracking. Zhuang, Y. Z and Xu L . (2017) conducted a theoretical analysis of the FLS. The authors also used numerical analysis to study the effect of the slab thickness, surface pavement material, and length of the debonded section on the FLS.

Many experimental studies and engineering practices have shown that various existing improvement measures can solve the structural defects of the FLS during the operation of the bridge to a certain extent. Given the macroscopic force characteristics of the FLS, the present paper proposes a new type of cast-inplace curved link-slab (CLS). Based on the theoretical derivation and numerical method, the mechanical properties of the CLS and FLS were analyzed and compared. Furthermore, the design parameters of the CLS were optimized using parametric sensitivity analysis.

\section{THEORETICAL ANALYSIS}

\section{Overview of CLS}


The structure of reinforced concrete CLS is shown in Fig. 1, which is mainly composed of longitudinally connecting steel bars, concrete pavement, and asphalt concrete surface layer. The longitudinal connecting steel bars are distributed on the upper and lower edges of the concrete pavement. The upper layer has a straight reinforcement, and the lower layer has curved support. The longitudinal steel bars at the upper and lower edges connect the bridge deck and the link slab. As shown in Fig. 1, the ends of the two adjacent SSBs are connected to achieve continuity and a no-joint deck.

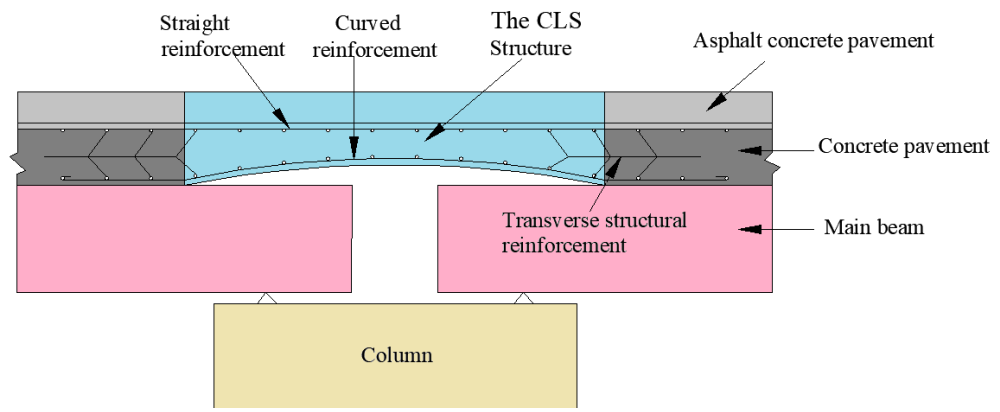

(a) Elevation of CLS

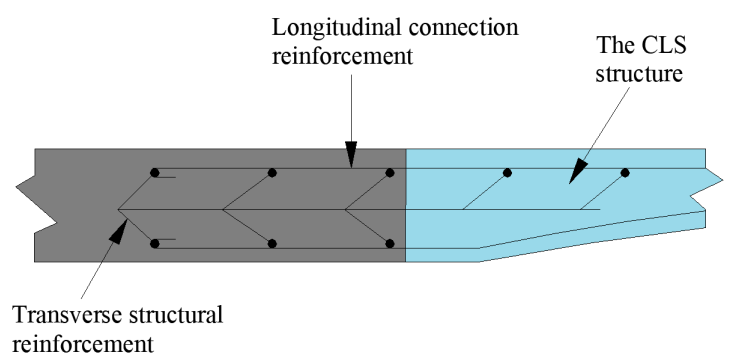

(b) Configuration of local rebar connection

Fig. 1. Structure of the reinforced concrete CLS

\section{Simplified Hingeless-arch Model}

The two ends of the CLS are consolidated with the adjacent SSBs. As a result, the cross-section of the curve structure increases from the dome to the curve foot. The law is consistent with the change in the internal force of the main curve ring so that each cross-section of the primary curve ring can exert maximum strength. Because of the relatively thin thickness of the bridge deck connection and the relatively small sagittal CLS span, the CLS variable cross-section is simplified to a hingeless-arch model for mechanical analysis (see 
Fig. 2).

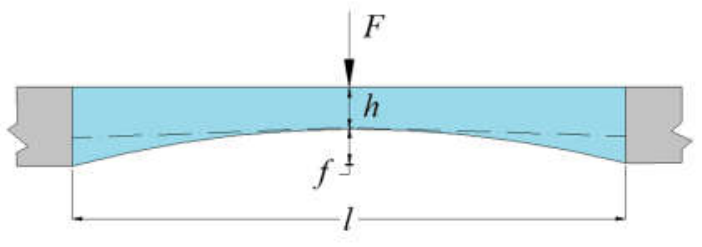

(a) Cross-section of the CLS

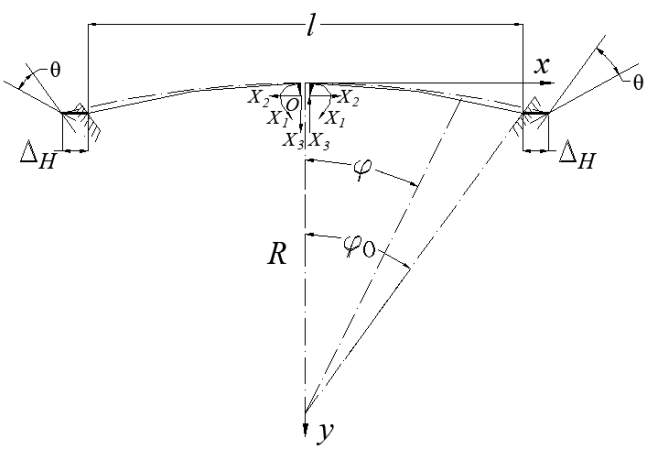

(b) Force diagram of the hingeless arch

Fig. 2. Simplified CLS structure

\section{Hingeless Arch Section Characteristics}

The CLS cross-section is composed of longitudinally stressed steel bars and concrete. Since the CLS section height varies, the section thickness has its smallest value in the middle of the span. Consider the mid-span section, as shown in Fig. 3, where $O_{c}$ is the neutral axis of the combined cross-section, $O_{s a}$ and $O_{s b}$ are the neutral axes of the upper and lower edges of the steel bar, and $B$ is the calculated width of the section. Let $a$ and $b$ refer to the CLS upper and lower surfaces, respectively. Then, the combined sectional moment of inertia for the CLS mid-span, $I$, is given by

$$
I=I_{c}+A_{c}\left(\frac{h}{2}-h_{c}\right)^{2}+I_{s a} \alpha_{E}+A_{s a} \alpha_{E}\left(h_{a}-h_{c}\right)^{2}+I_{s b} \alpha_{E}+A_{s b} \alpha_{E}\left(h_{b}-h_{c}\right)^{2}
$$

where $I_{c}=$ moment of inertia of the concrete section, $A_{c}=$ area of the concrete section, $h=$ height of the mid-span section, $h_{c}=$ distance from the neutral axis of the combined cross-section to the bottom of the crosssection, $I_{s a}, I_{s b}=$ moments of inertia for steel bar section at the upper and lower edge respectively, $A_{s a}, A_{s b}=$ total area of upper and lower edge steel bars, $\alpha_{E}=$ ratio of the coefficient of the elastic modulus of steel bar to that of the concrete, and $h_{a}, h_{b}=$ distances from the neutral axis of the upper and lower longitudinal bars to the bottom edge of the cross-section, respectively. 


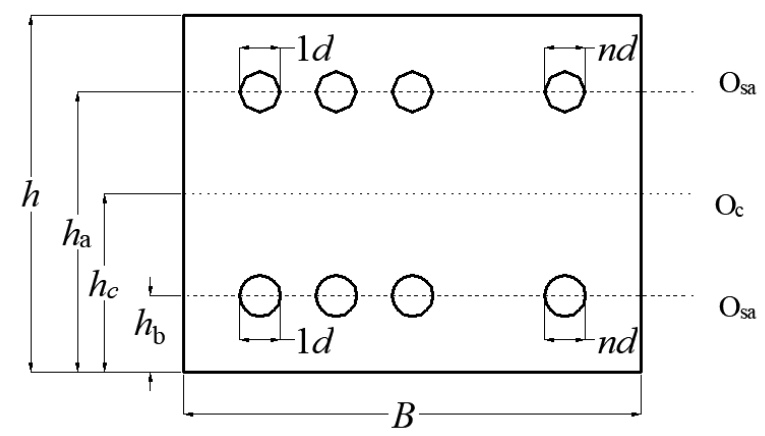

Fig. 3. Geometry of the neutral axis of the combined section Change $\mathrm{b}$ to $\mathrm{B}$ and $\mathrm{h} 1$ and $\mathrm{h} 2$ to ha and $\mathrm{hb}$

\section{Mechanical Analysis of CLS}

\section{Vehicle Loading}

Because the lower part of the CLS is vacant, the extrusion of the beam end displacement on the link-slab is avoided. Therefore, when the main beam undergoes an angular displacement under vehicle load, due to the restraint between the beam end structures, the CLS will also produce the same angular displacement, as shown in Fig. 4. In the figure, $L_{l}$ is the calculated span of the main beam, $H$ is the height of the main beam, $\theta$ is the angular displacement at the main-beam end, $\Delta H$ is the longitudinal displacement of the CLS due to the corner of the beam end, and $l$ is the CLS span length, $e$ is the distance from the bridge support to the beam end, $C$ is the gap between the adjacent main beams, and $d$ is the distance between the arch foot and the support.

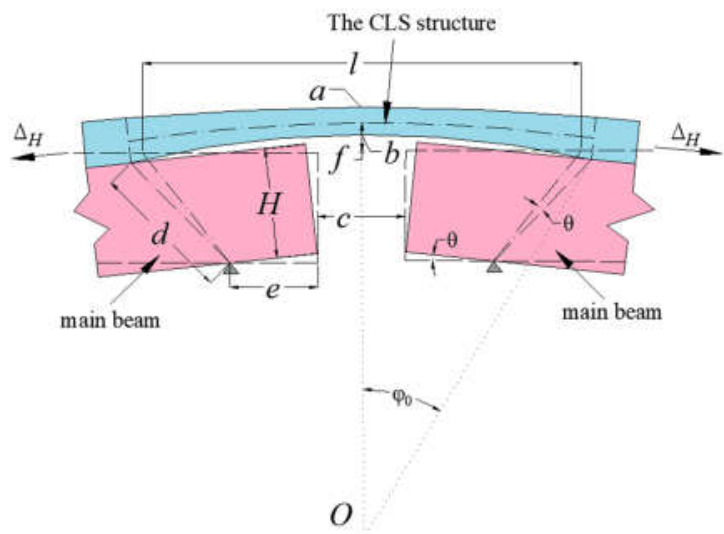

Fig. 4. Deformation of the beam end structure 
Because the CLS has less restraint on the main girder, ignore the CLS's restraint on the main girder and approximate a single-span SSB bridge. The structural mechanic's diagram multiplication method is used to calculate the maximum angular displacement of the beam end as

$$
\theta=\frac{L_{1}}{6 E_{1} I} P_{i}\left(L_{1}-l_{i}\right)\left\{1-\frac{\left(L_{1}-l_{i}\right)^{2}}{L_{1}^{2}}\right\}
$$

where $E_{l}=$ elastic modulus of the main beam at the left end, $I=$ moment of inertia of the main beam section, $P_{i}=$ vehicle axle load, and $l_{i}=$ distance between vehicle axle load $P_{i}$ and the beam end A.

Because the angular displacement $\theta$ of the beam end is small when the vehicle is loaded, the longitudinal displacement value of the CLS is approximated as the arc length $\Delta H$ of the angular displacement, namely:

$$
\Delta H=\frac{\theta}{180} \pi \sqrt{H^{2}+\left(e-\frac{l-c}{2}\right)^{2}}
$$

The distance $y_{s}$ from the elastic center to the vault can be calculated by the elastic center method as

$$
y_{s}=\frac{\int \frac{y}{E I} d s}{\int \frac{1}{E I} d s}=\frac{2 \int_{0}^{\varphi_{0}} R(1-\cos \varphi) R d \varphi}{2 \int_{0}^{\varphi_{0}} R d \varphi}=\frac{R\left(\varphi_{0}-\sin \varphi_{0}\right)}{\varphi_{0}}
$$

When the hingeless arch feet produces relative displacements, as shown in Fig. 2(b), the corresponding angular displacement $\Delta_{l c}$, horizontal displacement $\Delta_{2 c}$ and vertical displacement $\Delta_{3 c}$ will occur at the elastic center O. Solving the unknown force at the center of elasticity, Then

$$
\left\{\begin{array}{l}
X_{1}=-\frac{2 \theta}{2 \int_{0}^{\varphi_{0}} \frac{1}{E I} R d \varphi} \\
X_{2}=-\frac{2\left(f-y_{s}\right)+2 \Delta_{H}}{2 \int \frac{\bar{M}_{2}^{2}}{E I} d s+2 \int \frac{\bar{F}_{N 2}^{2}}{E A} d s} \\
X_{3}=-\frac{l \cdot \theta}{2 \int_{0}^{\varphi_{0}} \frac{x^{2}}{E I} R d \varphi}
\end{array}\right.
$$

where $\mathrm{X}_{1}$ is the bending moment, $\mathrm{X}_{2}$ is the horizontal force, and $\mathrm{X}_{3}$ is the vertical force. The bending moment of the CLS's vault section and the stress at the upper and lower surfaces are given by 


$$
\left\{\begin{array}{c}
M=X_{1}-X_{2}\left(y_{s}+h_{c}-\frac{h}{2}\right) \\
\sigma_{a}=\frac{M}{W_{o a}}=\frac{M}{I_{t} /\left(h-h_{c}\right)} \\
\sigma_{b}=\frac{M}{W_{o b}}=\frac{M}{I_{t} / h_{c}}
\end{array}\right.
$$

The stress $\sigma_{\mathrm{s}}$ produced by the axial force $X_{2}$ is given by

$$
\sigma_{s}=\frac{X_{2}}{A_{0}}
$$

Therefore, the stresses at points a and $\mathrm{b}$ under a load of a mid-span vehicle are given by

$$
\left\{\begin{array}{l}
\sigma_{q a}=\sigma_{a}+\sigma_{s} \\
\sigma_{q b}=\sigma_{b}-\sigma_{s}
\end{array}\right.
$$

Vehicle Braking Force

An SSB bridge can be regarded as a continuous structural system when the longitudinal horizontal force acts on it. In addition to the stress caused by the overall temperature change, the longitudinal horizontal external force also influences the vehicle braking force on the safety of the bridge superstructure piers and supports.

The braking force of each car on the continuous SSB bridge is given by

$$
F_{z}=\frac{F_{i} \times \sum K_{i}}{K_{i}}
$$

where $F_{z}=$ vehicle braking force, $F_{i}=$ braking force of each abutment, and $K_{i}=$ integrated thrust stiffness of the i-th bearing and abutment.

Since the longitudinal horizontal force at the beam end is transmitted through the CLS and the bearing, the CLS will deform longitudinally under the vehicle braking force. When the vehicle braking force acts on the right span of the main beam, it can be regarded as adding a horizontal elongation displacement $\Delta L$ at the right end of the hingeless arch. That is,

$$
\Delta_{L}=\frac{F_{z}}{\sum K_{i}}
$$

where $\Delta_{L}=$ horizontal displacement of CLS under braking force. The unknown force at the center of elasticity is solved as 


$$
\left\{\begin{array}{l}
X_{1}=0 \\
X_{2}=-\frac{\Delta_{L}}{\frac{R^{3}}{E I}\left(\varphi_{0}-\frac{2 \sin ^{2} \varphi_{0}}{\varphi_{0}}+\sin \varphi_{0} \cos \varphi_{0}\right)+\frac{R}{E A}\left(\varphi_{0}+\sin \varphi_{0} \cos \varphi_{0}\right)} \\
X_{3}=0
\end{array}\right.
$$

Substituting Eq. (11) into Eqs. (7) and (8), the stresses at points $a$ and $b$ on the CLS's upper and lower surfaces under the vehicle braking force on the right span are given by

$$
\left\{\begin{array}{l}
\sigma_{y k a}\left(\sigma_{z k a}\right)=\sigma_{a}+\sigma_{s} \\
\sigma_{y k b}\left(\sigma_{z k b}\right)=\sigma_{b}-\sigma_{s}
\end{array}\right.
$$

Note that under the vehicle braking force on the left span, the CLS's deformation is opposite to that of the right-span vehicle.

\section{Temperature Gradient}

Under a positive temperature gradient, the main beam is thermally expanded and elongated, arched upward, and deflected downward at its end, resulting in a clockwise angular displacement $\theta_{z}$. In contrast, the structural deformation is the opposite under a negative temperature gradient, resulting in a counterclockwise angular displacement $\theta_{f}$.

The main girder changes linearly along the girder height under the temperature gradient and uniformly along the longitudinal and transverse bridge directions. According to the flat section's assumption, the main beam's neutral axis curvature after bending and deformation under the temperature gradient remains unchanged along the longitudinal direction, and the neutral axis curvature is $\beta$ (Shao et al., 2019). Thus, the beam end angular displacement $\theta$ can be obtained:

$$
\theta=\frac{L_{1}}{2} \frac{\alpha}{I} \int_{H} T(H) b(H)\left(H-H_{c}\right) d H
$$

where $\alpha=$ linear expansion coefficient of concrete, which is taken as $1.05 \times 10^{-5} / C, I=$ moment of inertia of the main beam section, $T(H)=$ temperature change function of the main beam section, $b(H)=$ function of the width of the main beam section along the beam height, $H_{c}=$ distance from the center of the main beam section 
to the bottom of the beam, and $H=$ height of the main beam section.

The force law equation is established, and the unknown force at the center of elasticity is solved as:

$$
\left\{\begin{array}{l}
X_{1}=\frac{E I \theta}{R \varphi_{0}} \\
X_{2}=-\frac{2\left(y_{s}-f\right)-2 \Lambda_{H}}{\frac{R^{3}}{E I}\left(\varphi_{0}-\frac{2 \sin ^{2} \varphi_{0}}{\varphi_{0}}+\sin \varphi_{0} \cos \varphi_{0}\right)+\frac{R}{E A}\left(\varphi_{0}+\sin \varphi_{0} \cos \varphi_{0}\right)} \\
X_{3}=\frac{l \cdot \theta}{\frac{R^{3}}{E I}\left(\varphi_{0}-\sin \varphi_{0} \cos \varphi_{0}\right)}
\end{array}\right.
$$

Substituting Eq. (14) into Eqs. (7) and (8), the stresses at points a and b on the CLS upper and lower surfaces under the positive (negative) temperature gradient are obtained as

$$
\left\{\begin{array}{l}
\sigma_{z w a}\left(\sigma_{f w a}\right)=\sigma_{a}+\sigma_{s} \\
\sigma_{z w b}\left(\sigma_{f w b}\right)=\sigma_{b}-\sigma_{s}
\end{array}\right.
$$

\section{Overall Temperature Change}

The overall temperature difference of the environment also has a prominent effect on the deformation of the bridge structure. The bridge deforms uniformly under the effect of the overall temperature change. When the overall temperature is higher than the closing temperature of the bridge deck, the beams elongate, and when the temperature is lower than the closing temperature, the beams shrink. For a single-span simply supported girder bridge, when the overall temperature changes uniformly, the deformation of the CLS $\Delta_{H}$ is twice the shrinkage deformation of the single-span main girder, namely:

$$
\Delta_{H}=2 \Delta_{L}=2 \alpha \Delta_{t} L
$$

where $\Delta t=$ difference between the calculated and ambient temperatures when the bridge is closed, and $L=$ span of the SSB. Then, the unknown force at the center of elasticity is solved as

$$
\left\{\begin{array}{l}
X_{1}=0 \\
X_{2}=-\frac{2 \alpha \Delta_{t} L}{\frac{R^{3}}{E I}\left(\varphi_{0}-\frac{2 \sin ^{2} \varphi_{0}}{\varphi_{0}}+\sin \varphi_{0} \cos \varphi_{0}\right)+\frac{R}{E A}\left(\varphi_{0}+\sin \varphi_{0} \cos \varphi_{0}\right)} \\
X_{3}=0
\end{array}\right.
$$

Substituting Eq. (17) into Eqs. (7) and (8), the stresses at Points $a$ and $b$ on the CLS's upper and lower surfaces 
are given by

$$
\left\{\begin{array}{l}
\sigma_{j a}\left(\sigma_{s a}\right)=\sigma_{a}+\sigma_{s} \\
\sigma_{j b}\left(\sigma_{s b}\right)=\sigma_{b}-\sigma_{s}
\end{array}\right.
$$

Note that when the beam is heated as a whole, the bridge deck has a continuous deformation.

\section{Stress Combination on CLS}

The stress formulas of the CLS under vehicle loading, vehicle braking force, temperature gradient, and overall temperature change were previously derived, and the stresses under the critical load conditions were combined (MTPRC, 2015). The maximum tensile stress on the CLS upper surface, $\sigma_{t \text { max } a}$, is given by

$$
\sigma_{t \max a}=\sigma_{q a}+\sigma_{y k a}+\sigma_{f w a}+\sigma_{j a}
$$

where $\sigma_{q a}=$ sum of bending and axial tensile stresses under vehicle load, $\sigma_{y k a}=$ tensile stress of the right-span vehicle braking force, $\sigma_{f w a}=$ sum of bending and axial tensile stresses under a negative temperature gradient, and $\sigma_{j a}=$ tensile stress under the overall temperature drop.

The maximum compressive stress on the CLS upper surface, $\sigma_{c \max a}$, is given by

$$
\sigma_{c \max a}=\sigma_{z w a}+\sigma_{z k a}+\sigma_{s a}
$$

where $\sigma_{z w a}=$ sum of bending and compressive stresses under a positive temperature gradient, $\sigma_{z k a}=$ compressive stress under braking force of the left-span vehicle, and $\sigma_{s a}=$ compressive stress under overall temperature rise.

The maximum tensile stress on the CLS lower surface, $\sigma_{t \max b}$, is given by

$$
\sigma_{t \max b}=\sigma_{z w b}+\sigma_{y k b}+\sigma_{j b}
$$

where $\sigma_{z w b}=$ sum of bending and axial tensile stresses under a positive temperature gradient, $\sigma_{y k b}=$ tensile stress under the braking force of the right-span vehicle, and $\sigma_{j b}=$ tensile stress under the effect of overall cooling.

The maximum compressive stress on the CLS lower surface, $\sigma_{c \max b}$, is given by

$$
\sigma_{c \max b}=\sigma_{q b}+\sigma_{z k b}+\sigma_{f w b}+\sigma_{s b}
$$


where $\sigma_{q b}=$ sum of bending and compressive stresses under vehicle load, $\sigma_{z k b}=$ compressive stress under the braking force of the left-span vehicle, $\sigma_{f w b}=$ sum of bending and compressive stresses under a negative temperature gradient, and $\sigma_{s b}=$ compressive stress under the overall heating.

\section{NUMERICAL ANALYSIS OF CLS AND FLS}

\section{Project Overview}

A two-span prestressed concrete T-shaped simply supported girder bridge was selected as the engineering support background to compare the mechanical characteristics of the CLS and FLS. The bridge has a span of $20 \mathrm{~m}$ in a particular area of China. Respectively model the actual engineering bridge with FLS and the bridge with CLS structure and perform the numerical analysis and compare the two link-slab structures. The longitudinal bridge section and mid-span cross-sectional views are shown in Fig. 5. The CLS is set at Pier 1, and the distance between the adjacent main girder beam ends is $8 \mathrm{~cm}$. The middle beam is $1.7 \mathrm{~m}$ wide, the side beams are $2.025 \mathrm{~m}$ wide, and the beam height is $1.5 \mathrm{~m}$. The single bridge deck comprises 7 T-beams, and each main girder is equipped with two plate rubber bearings. The distance between the center of the support and the edge of the beam end is $0.22 \mathrm{~m}$. The CLS is shown in Fig. 6 . The section of the bridge link slab is densely arranged with steel bars. The steel bars are HRB335 steel bars with a diameter of $16 \mathrm{~mm}$, and the spacing between the bars is $100 \mathrm{~mm}$.

\section{Finite Element Modeling}

The bridge substructure is of little significance in analyzing the mechanical performance of the link-slab structure. Therefore, the model bridge only establishes the FLS and CLS structures. The model numerically analyzes the mechanical performance of the link-slab under different load conditions. ABAQUS was used to model the single middle beam of the superstructure of the SSB bridge. The model was divided into a total of 91,173 elements. 


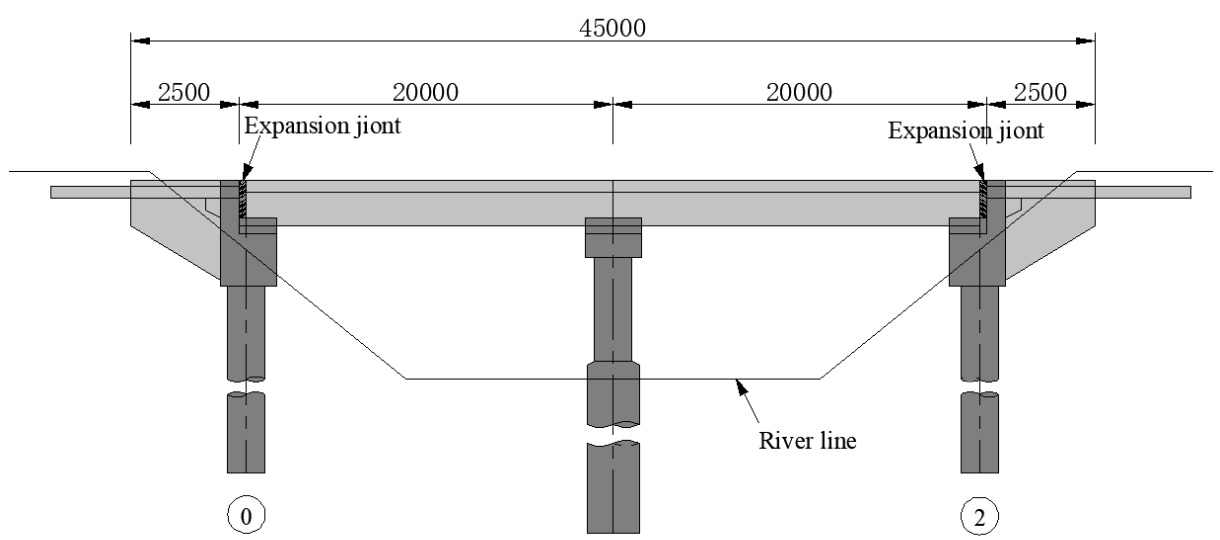

(1)

(a) Longitudinal section (unit: $\mathrm{mm}$ )

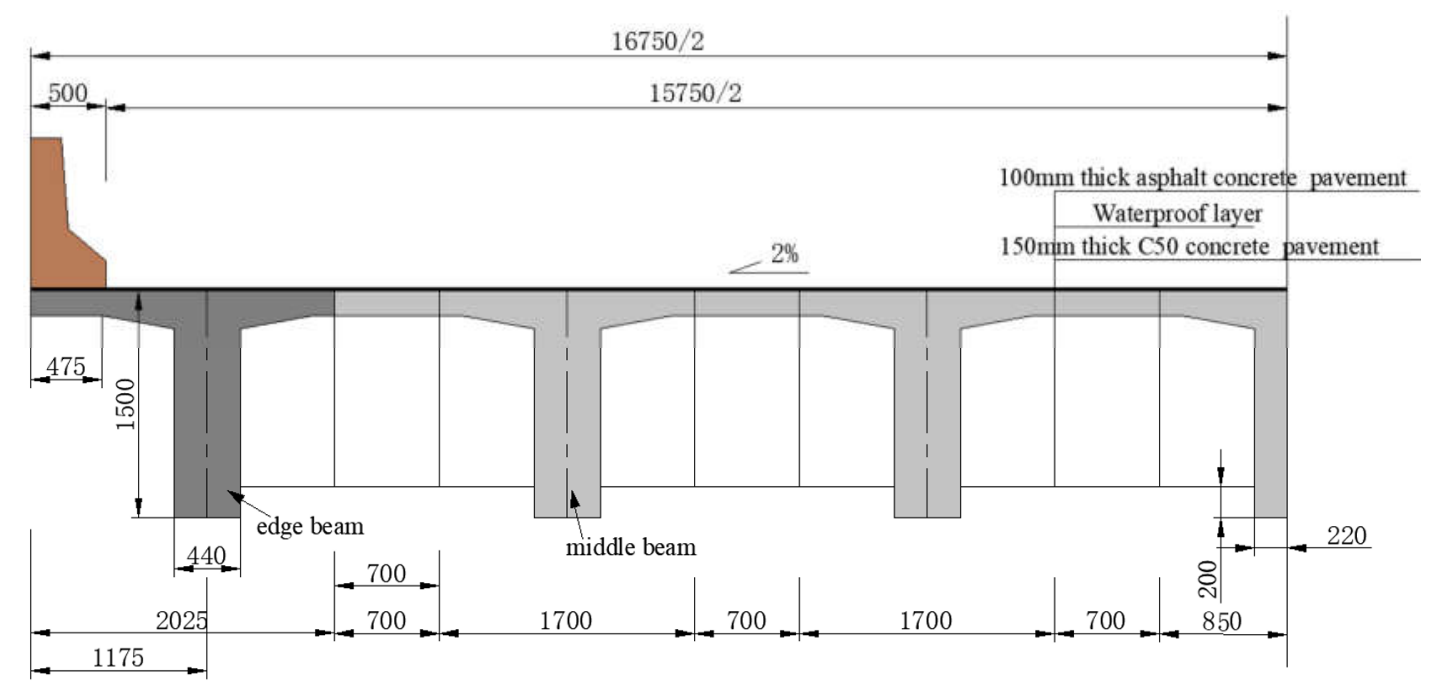

(b) Transverse cross-section (unit: $\mathrm{mm}$ )

Fig. 5. Overall diagram of the simply supported beam bridge

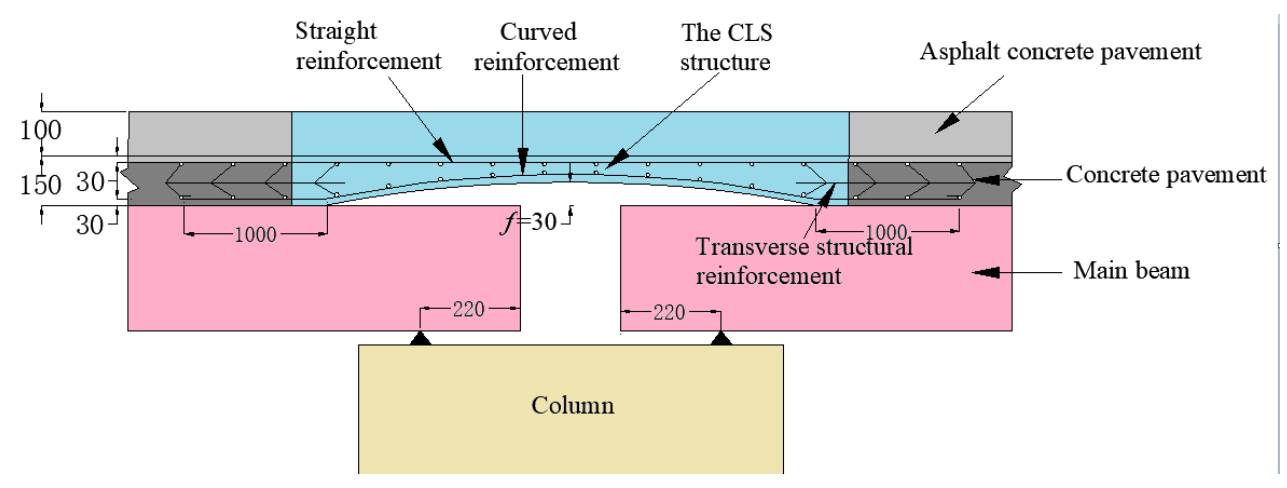

Fig. 6. Schematic of the CLS (unit: $\mathrm{mm}$ )

In the overall coordinate system of the model, the $\mathrm{X}$-axis direction is the longitudinal bridge direction, 
and the $\mathrm{Y}$-axis direction is the beam height direction. The $\mathrm{Z}$-axis direction is the transverse bridge direction, and the grid division results are shown in Fig. 7. The concrete structure is simulated by a hexahedral linear reduction integral unit (C3D8R). The element type used for prestressed steel strands and steel bars is a twonode three-dimensional truss element (T3D2). The beam end support of the main beam is a plate rubber support. The support was simulated using a three-way grounding spring element.

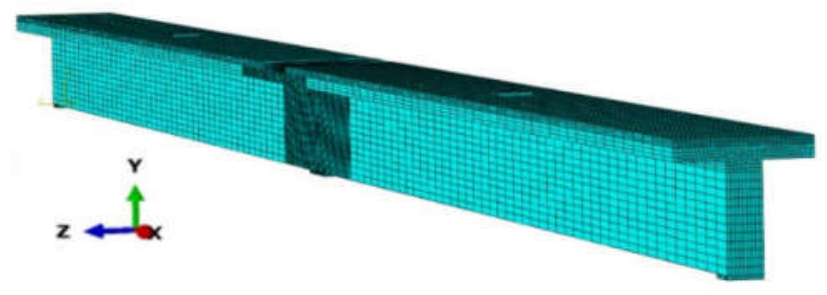

Fig.7. Schematic of the main beam mesh

\section{Data Analysis}

Since only elastic analysis is performed on this study's FLS and CLS structures, only the materials' elastic modulus, density, and linear expansion coefficient are defined when setting the material properties in the modelling process. The yield of the steel bar and the stress-strain relationship of the material change linearly. The elastic analysis process considers the FLS and CLS results under loading conditions, such as the Second Phase Dead Load, Highway Class I Lane Load, Vehicle Braking Force, Overall Temperature Change, and Temperature Gradient. Also, the comparison and analysis of the FLS and CLS numerical results are carried out. Given the length of the space, when the vehicle braking force is on the left span of the main girder, the overall cooling change and the positive temperature gradient and other load conditions can be used for similar analysis.

\section{The Second Phase Dead Load}

As noted in Fig. 8, under the second phase dead load, the FLS produces stress concentration in the middle of the span. The tensile stress on the upper surface and compressive stress on the lower surface gradually decrease from the mid-span to the ends and tends to be gentle. The main tensile stress at the mid-span is 2.61 
$\mathrm{MPa}$, the main compressive stress at the mid-span is $-3.81 \mathrm{MPa}$; both are less than the ultimate strength of concrete. Under the second phase dead load, for the CLS, the stress on its upper surface and the stress on its lower surface gradually increases from the mid-span to the two ends, the principal compressive stress at the mid-span is $-0.39 \mathrm{MPa}$, and the main tensile stress is $0.22 \mathrm{MPa}$.. The main compressive stress at the midspan is $-0.62 \mathrm{MPa}$, and the main compressive stress at the beam end is $-1.25 \mathrm{MPa}$. Since there is no tensile stress in the weak part of the link-slab, no cracking at this part is expected.

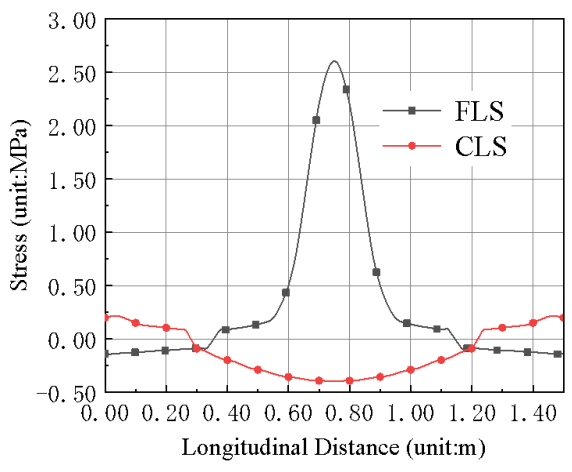

(a) Principal tensile stress on the upper surface

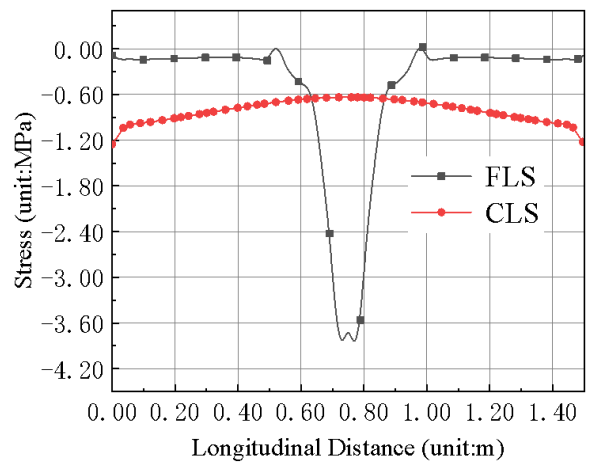

(b) Principal compressive stress on the lower surface

Fig. 8. Stress distribution on link-slab under the second phase dead load

\section{Highway Class I Lane Load}

Fig. 9 shows that under the load of the highway Class I lane, the FLS deformation and stress mode are similar to the second phase dead load. The tensile stress on the upper surface and compressive stress on the lower surface gradually decreases from the mid-span to the ends. The main tensile stress in the mid-span is 3.51 $\mathrm{MPa}$, which is greater than the tensile limit value of the concrete, so the upper surface of the mid-span part is cracked. The principal compressive stress at the mid-span is $-5.54 \mathrm{MPa}$. The upper surface stress of the CLS gradually increases from the mid-span to the end, where the concentrated load is applied and reaches the maximum at the connection section between the link-slab and bridge deck. The maximum tensile stress is $1.23 \mathrm{MPa}$, which is less than the tensile limit of concrete. The principal compressive stress at the mid-span part is $-0.29 \mathrm{MPa}$. The lower surface stress change tends to be gentle, almost unchanged, presenting the 
principal compressive stress at the mid-span part of -1.02 MPa.

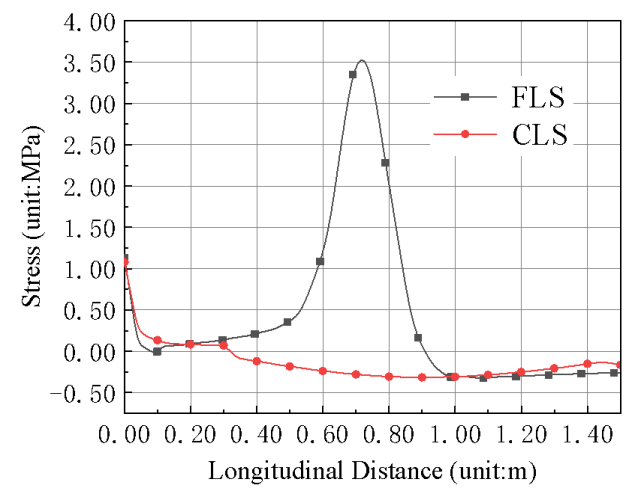

(a) Principal tensile stress on the upper surface

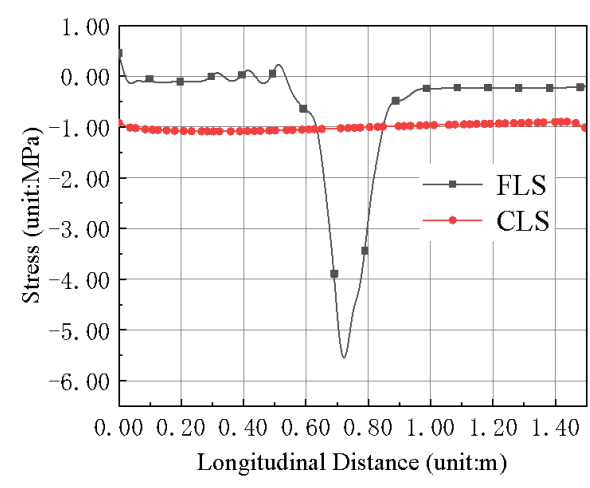

(b) Principal compressive stress on the lower surface

Fig. 9. Stress distribution on the link-slab under Highway-Class I load

\section{Vehicle Braking Force (Right Span)}

Fig. 10 shows that when the braking force of the vehicle acts on the right span of the adjacent main girder, the upper surface of the FLS is compressed, with the main compressive stress of $-0.36 \mathrm{MPa}$. The lower surface is under tension, experiencing the main tensile stress of 1.09 MPa. The upper surface of the CLS is under tension, and the stress distribution gradually increases from the mid-span to the ends. The main tensile stress at the mid-span part is $0.57 \mathrm{MPa}$, and the maximum normal stress is $0.57 \mathrm{MPa}$. The lower surface is also under tensile stress, and the distribution gradually decreases from the middle of the span to both ends.

The main tensile stress of the middle part of the span is $0.65 \mathrm{MPa}$, which are both less than the ultimate strength of concrete, not leading to the link-slab cracking.

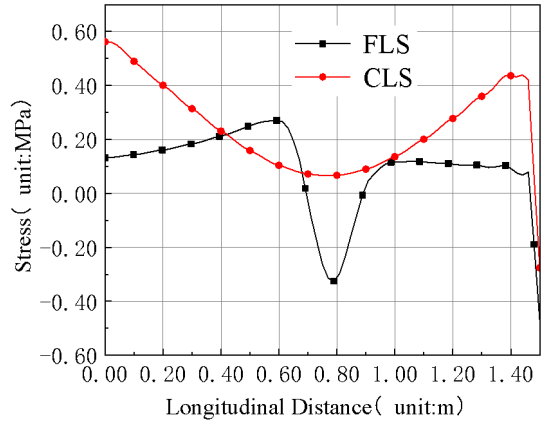

(a) Principal compressive stress on the upper surface

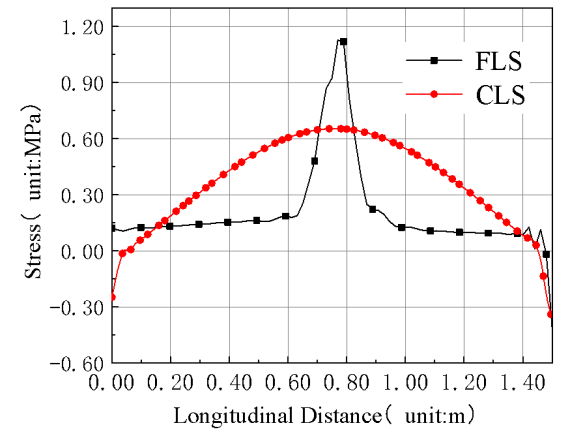

(b) Principal tensile stress on the lower surface

Fig. 10. Stress distribution on link-slab under vehicle braking force on the right-span 


\section{Overall Heating $\left(15^{\circ} \mathrm{C}\right)$}

Fig. 11 shows that when the overall temperature of the bridge superstructure is increased by $15^{\circ} \mathrm{C}$, the $\mathrm{FLS}$ produces stress concentration at the mid-span part, and its upper surface is under tension. The tensile stress distribution gradually decreases from the mid-span to the ends and tends to be gentle. The main tensile stress at the mid-span part is $3.27 \mathrm{MPa}$, which is greater than the concrete's tensile limit value, and the cracks appear on the upper surface in the middle of the span. The lower surface is compressed, the main compressive stress is -3.91 MPa. The CLS is tensioned on the upper surface of the mid-span part, and its tensile stress distribution gradually increases from the mid-span to the ends. The main tensile stress at the mid-span is $0.27 \mathrm{MPa}$. The principal tensile stress at the CLS end is $0.59 \mathrm{MPa}$, which is less than the tensile limit of concrete, where the lower surface is compressed, with a stress variation small along the CLS. The principal compressive stress at the mid-span part is $-0.45 \mathrm{MPa}$

\section{Negative Temperature Gradient}

From Fig. 12, in the FLS, the principal tensile stress on the upper surface of the mid-span part is $5.81 \mathrm{MPa}$, which is greater than the tensile limit of concrete, and cracks appear. The principal compressive stress on the lower surface is -5.43 MPa. For CLS, the principal tensile stress on the upper surface mid-span is $1.90 \mathrm{MPa}$, which is less than the tensile limit of concrete. The principal compressive stress on the lower surface midspan is $-0.40 \mathrm{MPa}$, and the variation range of stress change is small.
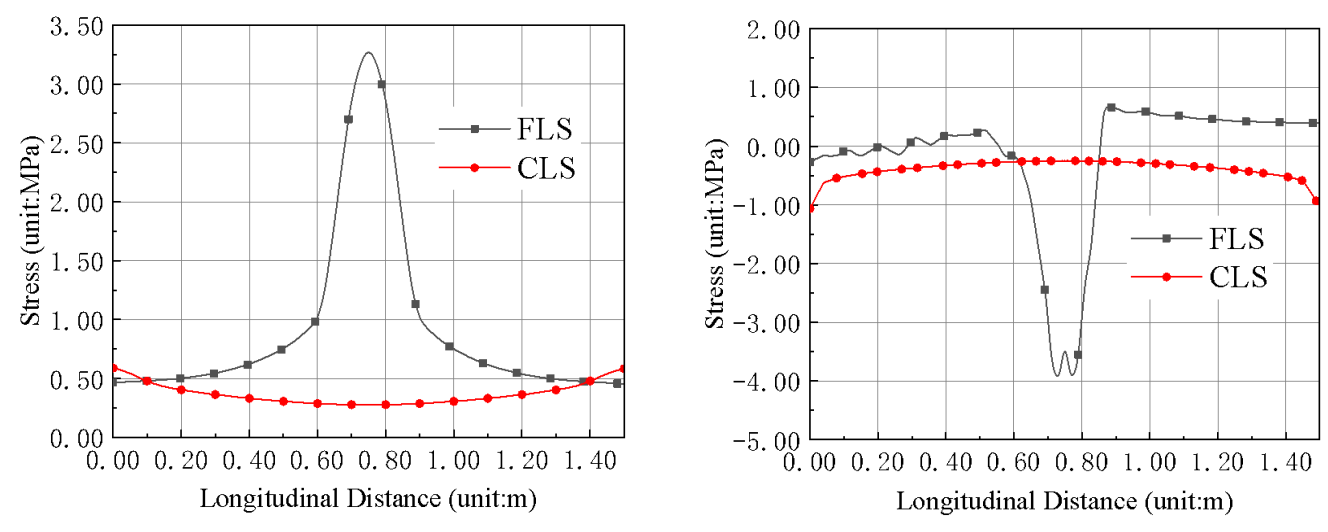
(a) Principal tensile stress on the upper surface

(b) Principal compressive stress on the lower surface

Fig. 11. Stress distribution on link-slab under global warming

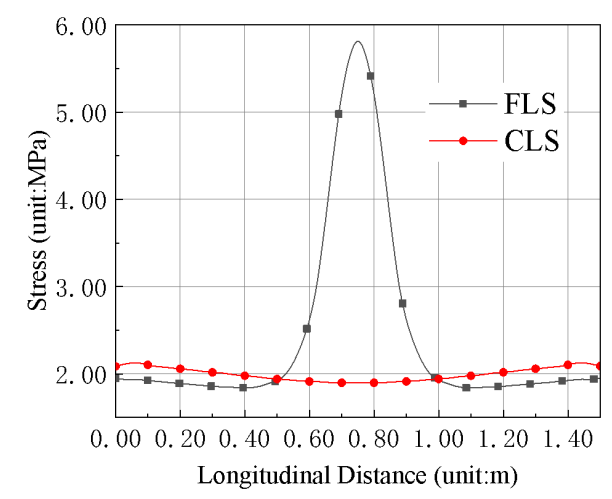

(a) Principal tensile stress on the upper surface

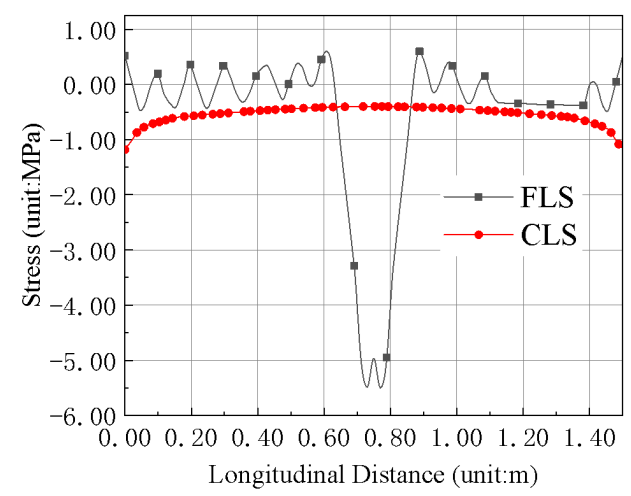

(b) Principal compressive stress on the lower surface

Fig. 12. Stress distribution on the link-slab under negative temperature gradient

This comparison shows that, under different load conditions in the longitudinal direction of the bridge,

the FLS pavement has the most stress change in the middle of the span where it reaches a peak value. This value is greater than the tensile strength of the concrete, resulting in cracks on the bridge deck. The CLS structure dramatically reduces the contact and the squeezing effect of the concrete at the main beam end on the bridge deck, as well as the stress of the CLS's concrete pavement. The stress distribution of the CLS pavement is controlled within the range of concrete strength, thus effectively preventing the cracking of the bridge deck.

\section{SENSITIVITY ANALYSIS OF CLS}

Many studies have shown that, without changing the bridge type and load conditions, the factors affecting the CLS mechanical properties include reinforcement ratio, pavement thickness, surface material, and the CLS span. A numerical analysis of different parameters was conducted to determine the influence on the CLS's mechanical properties and help optimize the CLS design. The load conditions are shown in Table 1. By analyzing the CLS's stress conditions under the most unfavourable load factors, the same eight load conditions were carried out according to MTPRC (2015). According to Table 2, the conditions correspond to 
load Combinations I, II, III, and IV for the ultimate state of the bearing capacity.

Table.1. Load conditions

\begin{tabular}{cc}
\hline Numbering & Load condition \\
\hline 1 & Second Phase Dead Load \\
2 & Highway I Lane Load \\
3 & Vehicle Braking Force (Right Span) \\
4 & Vehicle Braking Force (Left Span) \\
5 & Overall Cooling $25^{\circ} \mathrm{C}$ \\
6 & Overall Heating $15^{\circ} \mathrm{C}$ \\
7 & Negative Temperature Gradient \\
8 & Positive Temperature Gradient \\
\hline
\end{tabular}

Table 2. Load combination conditions

\begin{tabular}{cccccccc}
\hline \multirow{2}{*}{ Load Combination } & \multicolumn{7}{c}{${\text { Load Safety Factor }{ }^{\mathrm{a}}}$} \\
\cline { 2 - 8 } & $\mathrm{DL}$ & $\mathrm{P}$ & $\mathrm{C} \& S$ & $\mathrm{CL}$ & TG & TR\&F & VBF \\
\hline I & 1.2 & 1.0 & 1.0 & 1.4 & $0.8 \times 1.4$ & $0.8 \times 1.4$ & $-\mathrm{b}$ \\
II & 1.2 & 1.0 & 1.0 & $0.8 \times 1.4$ & 1.4 & 1.4 & $-\mathrm{b}$ \\
III & 1.2 & 1.0 & 1.0 & 1.4 & $0.8 \times 1.4$ & $0.8 \times 1.4$ & $0.8 \times 1.7$ \\
IV & 1.2 & 1.0 & 1.0 & $0.7 \times 1.4$ & 1.4 & 1.4 & $0.7 \times 1.4$ \\
\hline
\end{tabular}

${ }^{a} \mathrm{DL}=$ dead load, $\mathrm{P}=$ prestressed, $\mathrm{C} \& \mathrm{~S}=$ creep and shrinkage, $\mathrm{CL}=$ carload (including impact), $\mathrm{TG}=$ temperature gradient, $\mathrm{TR} \& \mathrm{~F}=$ temperature rise and fall, and $\mathrm{VBF}=$ vehicle breaking force. ${ }^{\mathrm{b}}$ Not applicable.

\section{Reinforcement Ratio of CLS}

Considering that the reinforcement of the pavement of the link-slab on SSB bridge is relatively random in the design, this section will analyze the influence of the reinforcement ratio $(0.7 \%, 1.6 \%, 2.9 \%, 3.6 \%, 4.5 \%)$ on the mechanical performance of the CLS without changing the pavement thickness. The elastic analysis method is used to calculate the maximum stress on the upper and lower surfaces of the CLS with different reinforcement ratios under various working conditions and load combinations.

The results are shown in Fig. 13. As noted, with the increase in the reinforcement ratio, the maximum principal tensile stress and principal compressive stress on the upper surface of the CLS decrease, the maximum principal tensile stress of the upper surface under load combination III decreases from $0.97 \mathrm{MPa}$ to $0.59 \mathrm{MPa}$, and the maximum principal compressive stress on the upper surface under load combination IVdecreases from -4.59 MPa to -3.83 MPa. The maximum principal tensile stress and principal compressive stress on the lower surface increase. The maximum principal tensile stress of the bottom surface under load 
combination II increases from $0.44 \mathrm{MPa}$ to $0.77 \mathrm{MPa}$. The maximum principal compressive stress on the bottom surface under load Combination I increases from -0.89 MPa to -1.48 MPa. Both the upper and lower surface tensile stresses are less than the concrete's tensile limit. Under the condition that the thickness of the CLS remains unchanged, the stress change amplitude of the CLS under different load conditions is small. Therefore, changing the reinforcement ratio of the CLS has a limited effect on the CLS stress performance.

\section{Pavement Thickness and Surface Material of CLS}

The CLS mechanical performance with asphalt concrete and direct concrete pavements are compared. Let $h_{l}$ and $h_{2}$ denote the concrete and asphalt surface thicknesses design scheme of CLS, respectively. The design schemes are shown in Table 3. Schemes 1 to 4 use an asphalt concrete surface layer and concrete pavement to form a superimposed structure. Schemes 5 to 8 directly use a concrete paving layer as the overall paving structure. The maximum stresses of the CLS upper and lower surfaces and the CLS stress changes under the most unfavourable load combinations are analyzed, as shown in Figs. 14 and 15, respectively.

Table 3. Thickness design scheme of CLS (mm)

\begin{tabular}{ccccc}
\hline $\begin{array}{c}\text { Thickness } \\
\text { Design Scheme }\end{array}$ & $\begin{array}{c}\text { Concrete Surface } \\
\text { Thickness } \\
h_{1}\end{array}$ & $\begin{array}{c}\text { Asphalt Surface } \\
\text { Thickness } \\
h_{2}\end{array}$ & $\begin{array}{c}\text { Rise of Curve } \\
f\end{array}$ & $\begin{array}{c}\text { Number of } \\
\text { Reinforcement } \\
\text { Mesh Layer }\end{array}$ \\
\hline 1 & 100 & 100 & 30 & 2 \\
2 & 150 & 100 & 30 & 2 \\
3 & 200 & 100 & 30 & 2 \\
4 & 250 & 100 & 30 & 2 \\
5 & 100 & 0 & 30 & 2 \\
6 & 150 & 0 & 30 & 2 \\
7 & 200 & 0 & 30 & 2 \\
8 & 250 & 0 & 30 & 2 \\
\hline
\end{tabular}




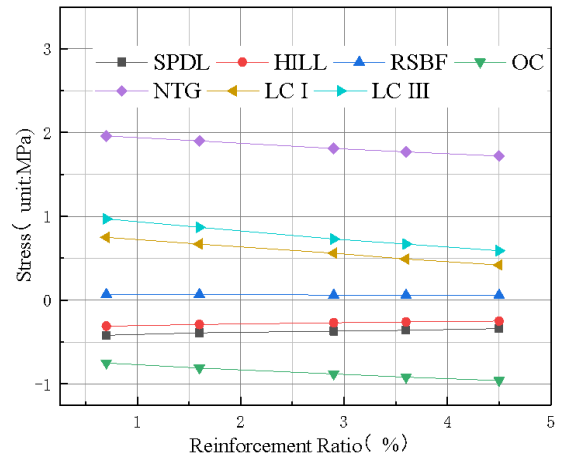

(a) Maximum tensile stress on upper surface

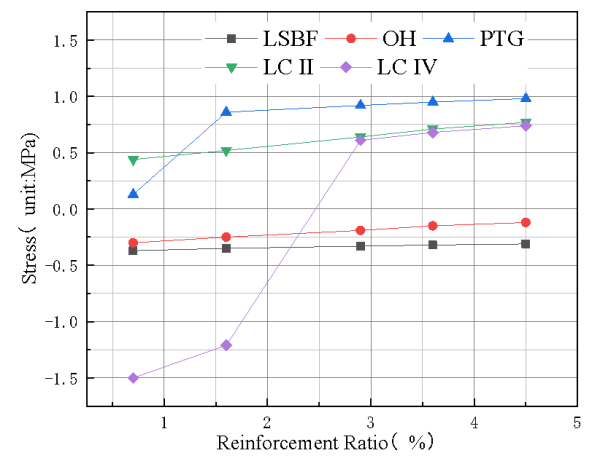

(c) Maximum tensile stress on the bottom surface

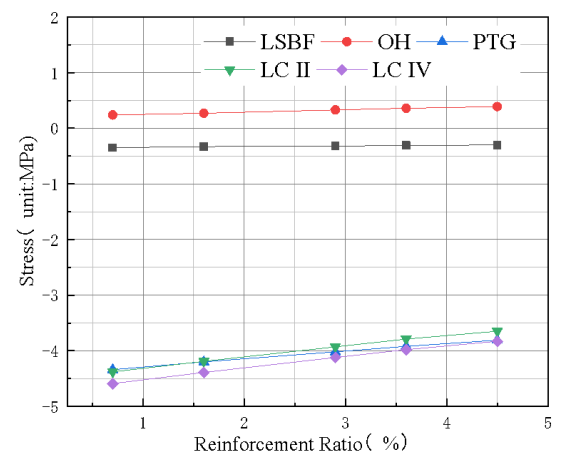

(b) Maximum compressive stress on upper surface

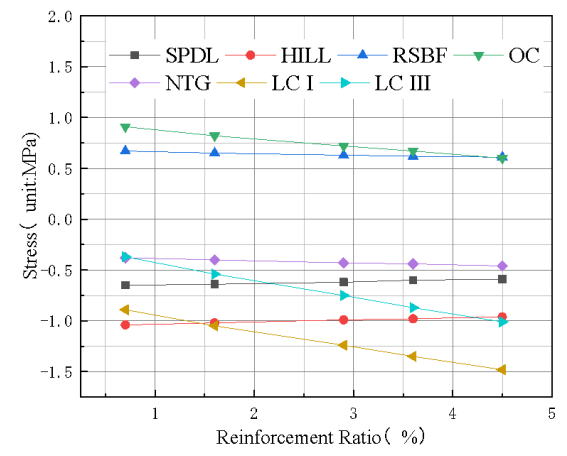

(d) Maximum compressive stress on the bottom surface

Fig. 13. Curve of maximum stress vs. reinforcement ratio of CLS (SPDL $=$ Second Phase Dead Load, HILL= Highway I Lane Load, RSBF = Right Span Braking Force, LSBF = Left Span Braking Force, OC = Overall Cooling $25^{\circ} \mathrm{C}, \mathrm{OH}=$ Overall Heating $15^{\circ} \mathrm{C}, \mathrm{NTG}=$ Negative Temperature Gradient, $\mathrm{PTG}=$ Positive Temperature Gradient, LC I = load Combination I, LC II = load Combination II, LC III = load Combination III, and LC IV = load Combination IV).

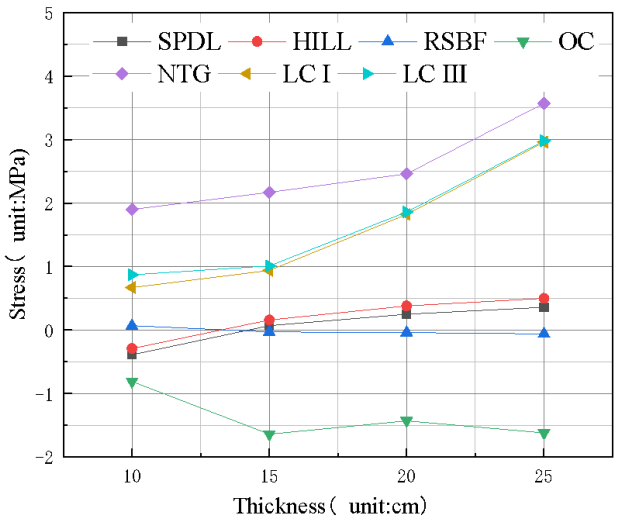

(a) Upper surface

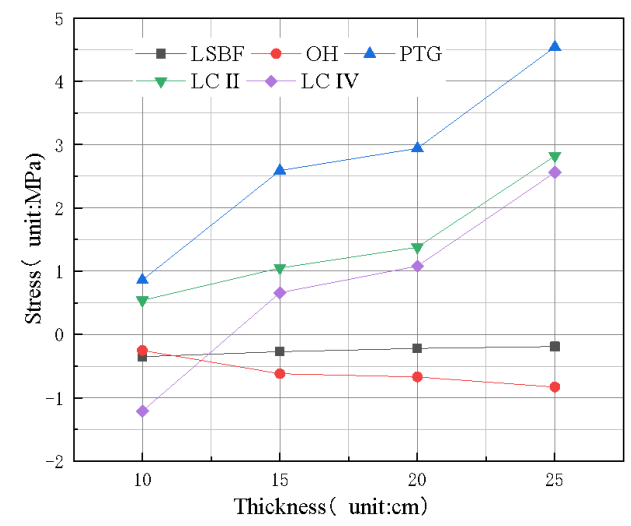

(b) Lower surface

Fig. 14. Curve of maximum principal tensile stress vs. thickness of CLS with asphalt concrete surface 


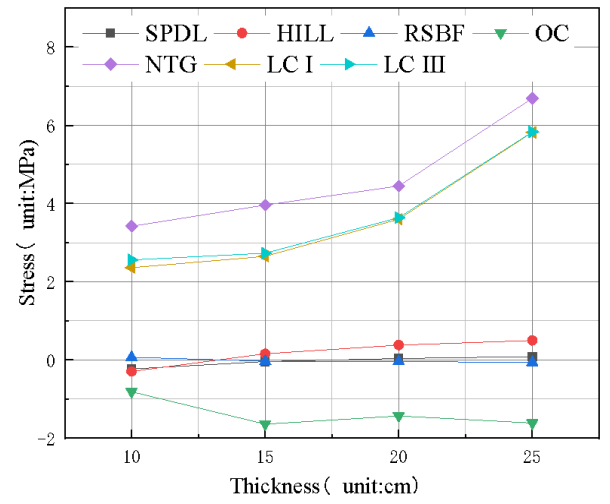

(a) Upper surface

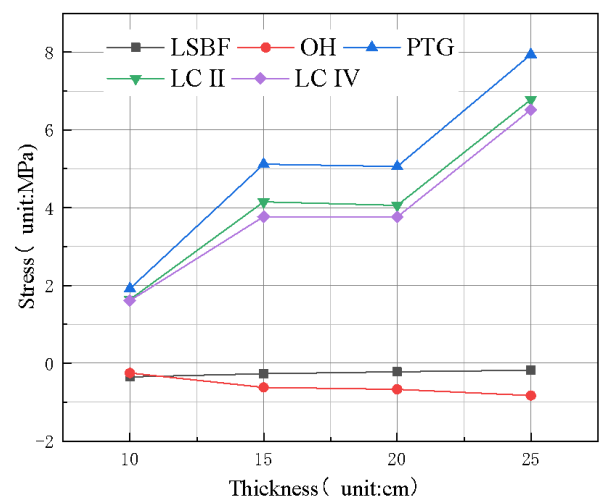

(b) Lower surface

Fig. 15. The curve of maximum principal tensile stress vs. thickness of CLS with concrete pavement

As noted, the maximum principal tensile stress of the CLS upper and lower surfaces with the asphalt concrete pavement and the concrete pavement directly increases as the thickness of the pavement increases under the corresponding load conditions. Under load Combination I, when the thickness of pavement of CLS increases from $10 \mathrm{~cm}$ to $25 \mathrm{~cm}$, the maximum principal tensile stress on the upper surface of the CLS asphalt concrete pavement increases from $0.75 \mathrm{MPa}$ to $2.98 \mathrm{MPa}$, which is close to concrete the tensile limit value. The maximum principal tensile stress of the upper surface of the CLS concrete pavement is increased from 2.56 MPa to 5.83 $\mathrm{MPa}$ when no asphalt layer is applied, which is greater than the tensile limit value of the concrete. Under load Combination II, the maximum principal tensile stress of the CLS lower surface increases as the thickness increases from $0.53 \mathrm{MPa}$ to $2.66 \mathrm{Mpa}$, which is less than the tensile limit of concrete. The maximum principal tensile stress of the CLS's lower surface increases with the thickness from 1.71 MPa to 6.72 MPa, and the range of tensile stress changes partially exceeds the tensile limit of concrete.

The pavement thickness should not be too small as small thickness will affect the vertical bearing capacity of the continuous structure of the bridge deck and cause premature damage to the structure. On the other hand, the thickness should not be too large as it will increase the cost and the overall rigidity of the bridge link slab. It is not conducive to structural deformation and affects the structure's stress. Combined with the tensile limit of concrete, the pavement thickness of the CLS is reasonable when the value is $15 \mathrm{~cm}$ to 
$20 \mathrm{~cm}$. This structure can solve the cracking problem of the link-slab to a certain extent.

Comparing the CLS with asphalt concrete and concrete as the surface pavement, as the thickness increases, the tensile stresses on the upper and lower surfaces gradually increase. However, the tensile stress value of the latter is greater than the former when the thickness is the same. At the same time, to facilitate construction and keep the structure consistent with the entire bridge deck pavement, it is more reasonable to use asphalt concrete as the paving layer of the CLS under the same thickness.

\section{Span of CLS}

Without changing the CLS pavement thickness and surface material, appropriately increasing the span can effectively reduce the bending and tension stiffness of the CLS structure. This behaviour makes the isolation space between the lower part of the link-slab and the main beam larger, which is beneficial to the coordinated deformation of the beam end displacement. In this section, numerical analysis is used to evaluate the effect of the preset curve span length on the CLS's mechanical properties. The preset span lengths are $1 \mathrm{~m}, 1.5 \mathrm{~m}$, $2.0 \mathrm{~m}, 3 \mathrm{~m}$, and $4 \mathrm{~m}$, which are $2.5 \%, 3.75 \%, 5 \%, 7.5 \%$, and $10 \%$ of the main girder length, respectively. According to the numerical results, the maximum principal tensile stress of the upper and lower surfaces of the CLS pavement under different loads and load combinations are shown in Fig. 16.

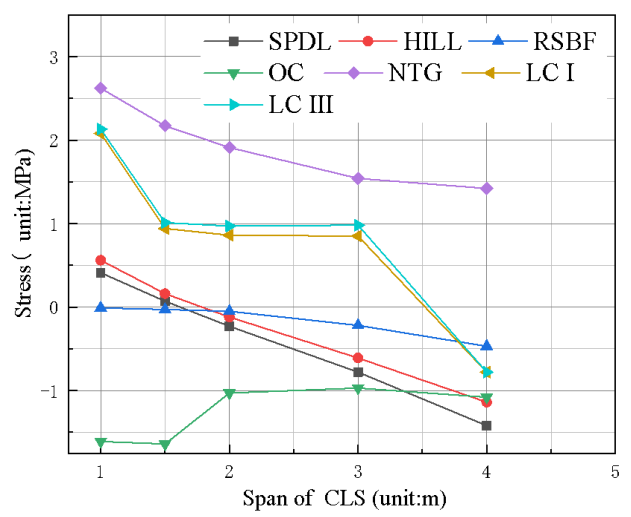

(a) Upper surface

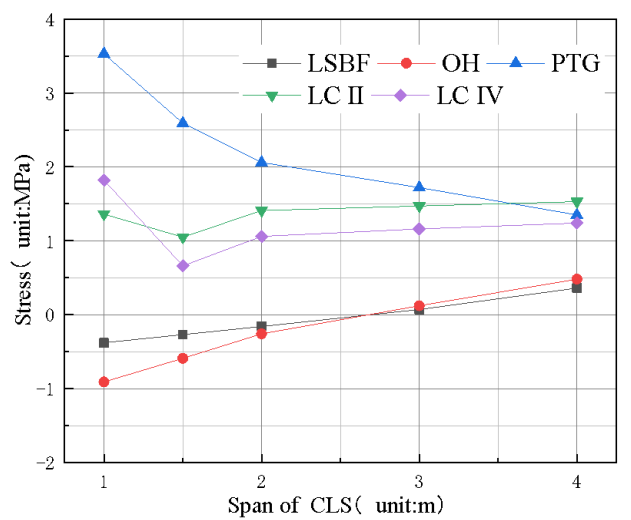

(b) Lower surface

Fig. 16. Curve of the maximum principal tensile stress vs. CLS span

It can be seen from Fig. 16 shows that under the corresponding load conditions, the maximum principal 
tensile stress on the upper surface of the mid-span part of the CLS structure of the CLS decreases with the increase of the curve-shape span. As noted, when the span length increases from $1 \mathrm{~m}$ to $2 \mathrm{~m}$, the maximum principal tensile stress of the upper surface under load Combination I decreased from 2.13 MPa to 0.97 $\mathrm{MPa}$ (54.5\% difference), while it decreased from $2.15 \mathrm{MPa}$ to $0.97 \mathrm{MPa}$ (54.9\% difference). The maximum principal tensile stress of the lower surface decreases first and increases as the curve span length increases. When the span length increases from $1 \mathrm{~m}$ to $2 \mathrm{~m}$, the maximum principal tensile stress of the lower surface increases from 1.45 MPa to 1.47 MPa under load Combination II (1.4\% difference), while it decreases from 1.82 MPa to $1.06 \mathrm{MPa}$ (41.7\% difference) under load Combination IV.

When the span length is $2 \mathrm{~m} \sim 3 \mathrm{~m}$, the main tensile stress value of the CLS upper and lower surfaces tends to be stable. However, when the span length increases, the CLS stress does not change significantly, and it will also affect the integrity of the CLS, which is not conducive to the structure's strength. Therefore, when the CLS span is $2 \mathrm{~m}$ to $3 \mathrm{~m}$ (about $5 \% \sim 7.5 \%$ of the main girder length), the main tensile stress on the CLS upper and lower surfaces tends to be stable and reasonable.

\section{Comparison of Numerical and Theoretical Results}

Through parameter sensitivity analysis, the CLS design was optimized, and it was numerically analyzed and theoretically calculated according to the optimal design plan (see Table 4). The optimal design parameters are as follows: the asphalt concrete pavement and concrete pavement of the CLS are $10 \mathrm{~cm}$ and $15 \mathrm{~cm}$ thick, respectively, the curve span is $2 \mathrm{~m}$ long and is $3 \mathrm{~cm}$ high, and the steel bar configuration is $16 @ 10 \mathrm{~cm}$ (reinforcement ratio 2.9\%). Table 4 shows that the theoretical results of the CLS are similar to the numerical analysis estimates. The theoretical results are larger than the corresponding numerical ones, indicating that the theoretical results are conservative, which is more conducive to structural safety. It also further verifies the rationality of the stress formula derived from the simplified model of the hingeless arch, which can 
provide a theoretical basis for the design of the CLS.

Table 4. Maximum stresses on the upper and lower surfaces of CLS span

\begin{tabular}{lccc}
\hline \multicolumn{1}{c}{ Stress Location } & Stress & Type & Stress Value $(\mathrm{MPa})$ \\
\hline Upper surface & Maximum tensile stress & Theoretical & 1.06 \\
& & Analysis & 0.97 \\
& Maximum compressive stress & Theoretical & -4.50 \\
& & Analysis & -4.14 \\
Lower surface & Maximum tensile stress & Theoretical & 0.86 \\
& & Analysis & 0.80 \\
& Maximum compressive stress & Theoretical & -1.16 \\
& & Analysis & -1.08 \\
\hline
\end{tabular}

\section{CONCLUDING REMARKS}

This paper has proposed a new type of CLS structure and has simplified it into a hingeless-arch model.

According to the theoretical deduction, the maximum stress formula for the middle part of the hingeless arch is obtained. The formula is numerically verified. The FLS and CLS bridge models were established using the finite-element software ABAQUS to analyze and compare them under different load conditions. Based on this study, the following comments are offered:

1. The design of the CLS enables the link-slab to form an isolation space with the main girder, which can release the tensile stress in the CLS. In addition, the curve structure weakens the thickness of the linkslab and reduces its bending, and tensile stiffness can better adapt to the deformation of the beam end structure and effectively solves the cracking problem of the link-slab.

2. Since both CLS ends are consolidated with the bridge deck pavement, the CLS is simplified into a hingeless-arch structure. According to the classical mechanical method, the hingeless arch simplified model is derived based on theoretical deduction. Formulas are derived for the maximum tension and compression stress on the upper and lower surfaces of the mid-span part of the link slab. In addition, the rationality of the stress formula is verified using the FEM simulation.

3. The sensitivity analysis showed that only changing the CLS section's reinforcement ratio has a limited 
impact on the CLS. The CLS with asphalt concrete pavement is more reasonable to keep the structure consistent with the overall bridge deck pavement. Based on the combined concrete tensile and compression limits, the CLS thickness should be $15 \mathrm{~cm}$ to $20 \mathrm{~cm}$, and its design span should be about $5 \% \sim 7.5 \%$ of the main beam length.

\section{Data Availability Statement}

All data, models, or codes that support the findings of this study are available from the corresponding author upon reasonable request.

\section{Acknowledgments}

The authors are grateful for the financial support provided by the National Natural Science Foundation of China (Grant No. 51774177) and the Natural Science Foundation of Zhejiang Province (Grant No. LY17E080022).

\section{Notation}

The following symbols are used in this paper:

$A_{s a}, A_{s b}=$ total area of upper and lower edge steel bars, respectively,

$A_{c}=$ area of the concrete section,

$a, b=$ upper and lower surfaces of the CLS, respectively

$B=$ calculated width of the section,

$b(H)=$ function of the width of the main beam section along the beam height,

$C=$ gap between adjacent main beams, and $d$ is the distance between the arch foot and the support,

$e=$ distance from the bridge support to the beam end,

$E_{l}=$ elastic modulus of the main beam at the left end, -

$F_{z}=$ vehicle braking force, 
$F_{i}=$ braking force of each abutment,

$h=$ height of the mid-span section,

$h_{a}, h_{b}=$ distances from the neutral axis of the upper and lower longitudinal bars to the bottom edge of the cross-section, respectively,

$=$ Concrete Surface thickness design scheme of CLS

$h_{1}, h_{2}=$ Concrete surface thickness and asphalt surface thickness design scheme of CLS, respectively,

$h_{c}=$ distance from the neutral axis of the combined cross section to the bottom of the cross-section,

$H=$ height of the main beam,

$H_{c}=$ distance from the center of the main beam section to the bottom of the beam

$I, I_{c}=$ moments of inertia of the main beam section and the concrete section, respectively,

$l_{i}=$ distance between vehicle axle load $P_{i}$ and the beam end A.

$I_{s a}, I_{s b}=$ moments of inertia for steel bar section at the upper and lower edges, respectively,

$K_{i}=$ integrated thrust stiffness of the i-th bearing and abutment,

$l=$ CLS span length,

$L=$ span of the SSB,

$L_{l}=$ calculated span of the main beam,

$P i=$ vehicle axle load

$T(H)=$ temperature change function of the main beam section,

$y_{s}=$ distance from the elastic center to the vault

$\alpha=$ linear expansion coefficient of concrete,

$\alpha_{E}=$ ratio coefficient of the elastic modulus of steel bar to that of concrete,

$\Delta_{l c}, \Delta_{2 c}, \Delta_{3 c}=$ angular, horizontal, and vertical displacements, respectively, 
$\Delta H=$ longitudinal displacement of the CLS due to the corner of the beam end,

$\Delta_{L}=$ horizontal displacement of CLS under braking force,

$\Delta t=$ difference between the calculated and ambient temperatures when the bridge is closed,

$\sigma_{q a}=$ sum of bending and axial tensile stresses under vehicle load,

$\sigma_{q b}=$ sum of bending and compressive stresses under vehicle load,

$\sigma_{y k a}=$ tensile stress of the right-span vehicle under the braking force,

$\sigma_{y k b}=$ tensile stress of the right-span vehicle under the braking force,

$\sigma_{f w a}=$ sum of bending and axial tensile stresses under a negative temperature gradient,

$\sigma_{f w b}=$ sum of bending and compressive stresses under a negative temperature gradient,

$\sigma_{j a}=$ tensile stress under the overall temperature drop,

$\sigma_{j b}=$ tensile stress under the effect of overall cooling,

$\sigma_{z w a}=$ sum of bending and compressive stresses under a positive temperature gradient,

$\sigma_{z w b}=$ sum of bending and axial tensile stresses under a positive temperature gradient,

$\sigma_{z k a}=$ compressive stress under braking force of the left-span vehicle,

$\sigma_{z k b}=$ compressive stress under the braking force of the left-span vehicle,

$\sigma_{s a}=$ compressive stress under overall temperature rise,

$\sigma_{s b}=$ compressive stress under overall heating,

$\sigma_{t \max a}=$ maximum tensile stress on the CLS upper surface

$\sigma_{c \max a}=$ maximum compressive stress on the CLS upper surface

$\sigma_{\text {tmax } b}=$ maximum tensile stress on the CLS lower surface

$\sigma_{c \max b}=$ maximum compressive stress on the CLS lower surface

$\sigma_{\mathrm{s}}=$ stress produced by the axial force $X_{2}$, 
$\theta=$ angular displacement at the end of the main beam,

\section{REFERENCES}

Au, A., Lam, C., Au, J., and Tharmabala, B. (2013). Eliminating deck joints using debonded link slabs: Research and Field Tests in Ontario. Journal of Bridge Engineering, 18(8), 768-778

Ahn, J-H., Yoon, J-H. and Kim, J-H. (2011). Evaluation of the behaviour of abutment-pile connection in integral abutment bridge. Journal of Constructional Steel Research, 67(7),1134-1148.

Chen, B. C., Zhuang, Y. Z., Huang, F. Y., and Briseghella, B. (2019). Jointless bridges. 2nd ed, China Communication Press: Beijing, China (in Chinese).

Chen, Q. and Abu-Farsakh, M. (2015). Mitigating the bridge end bump problem: A case study of a new approach slab system with geosynthetic reinforced soil foundation. Geotextiles and Geomembranes, 44(1), $39-50$.

Fan, L. C. (1984). Prestressed concrete highway bridges in China. 12th Congress, Vancouver, B.C. Final Report, 1984, 15-27.

Caner, A. and Zia, P. (1998). Behavior and design of link slabs for jointless bridge decks. Journal-Prestressed Concrete Institute, 43(43): 68-81.

Charuchaimontri, T., Senjuntichai, T. and Limsuwan, E. (2008). Effect of lap reinforcement in link slabs of highway bridges. Engineering Structures, 30(2), 546-560.

Kendall, A. Keoleian, G. A., and Helfand, G. E. (2008) Integrated life-cycle assessment and life-cycle cost analysis model for concrete bridge deck applications. Journal of Infrastructure Systems, 14(3), 214-222.

Kim, Y. and Fischer, Y. (2004). Performance of bridge deck link slabs designed with ductile engineered cementitious composite. ACI Structural Journal, 101(6), 792-801. 
Matt, P. (1983). Status of segmental bridge construction in Europe. Journal-Prestressed Concrete Institute, 28(3), 104-125.

Ministry of Transportation of the People's Republic of China (2008). Concrete structure: Concrete highway bridge design. Volume 2, Beijing (in Chinese).

Ministry of Transportation of the People's Republic of China (2015). General code for design of highway bridges and culverts. JTG D60-2015, Beijing (in Chinese).

Saber, A. and Aleti, A. R. (2012). Behavior of FRP link slabs in jointless bridge decks. Advances in Civil Engineering, 140-148.

Shao, X. D, Zhou, Y. D, and Cao, J. H. (2019). Experimental study on the flexural performance of a new type of continuous bridge deck with steel SSBs. China Civil Engineering Journal, 52(12), 80-92 (in Chinese).

Su, L., Yang, X., and Hu, Z. L. (2005). Analysis of hollow slab bridge diseases and remedial measures for continuous structure of bridge deck. Technology of Highway and Transport, 2,100-103 (in Chinese).

Wang, C. Q, Shen, Y. G, and Wang G. (2016). Tests on the mechanical characteristics of the continuous structure of the hollow slab girder bridge deck. Journal of Zhejiang University (Engineering Science Edition), 50(8), 1438-1445 (in Chinese).

Wang, G, Xie X, and Wang, C. Q. (2014). Mechanical performance of arch-type continuous slab-deck on simply-suppoorted girder bridge. Journal of Zhejiang University (Engineering Science Edition) ,48(6): 1049-1057 (in Chinese)

Ward, D. J. (1983). An overview of prestressed segmental concrete bridges. Journal-Prestressed Concrete Institute Journal, 28(2), 120-131.

Yao, H. (2005). Early damage and prevention of continuous expansion joint on reinforced concrete bridge deck. Journal of Ningbo University (Science and Technology Edition), (18)2:261-263 (in Chinese). 
Zhuang, Y. Z, Xu L, and Cheng, J. F. (2017). Theoretical analysis of the mechanical characteristics of the continuous structure of the simply supported girder bridge deck. China Journal of Highway and Transport, 30(7), 73-85 (in Chinese). 